\title{
Fishermen Intentions Toward Floating Net Cage based on Technology Acceptance Model and Theory of Reasoned Action
}

\author{
Mokh Suef $^{1}$, Nani Kurniati ${ }^{1}$, and Farras Rahardini Azizah ${ }^{1}$
}

\begin{abstract}
In order to support offshore aquaculture in Indonesia, a floating net cage is being developed by Pusat Studi Kelautan ITS and will be placed in Sidoasri Village, Malang, Indonesia. The use of floating net cage will shift the habits of the fishermen. It will be very for the effort of developing the floating net cage if it will be rejected by the fishermen. Therefore, it is important to measure the factors influencing fishermen intention as a potential user to use the cage. In this paper, Technology Acceptance Model is integrated with Theory of Reasoned Action to identify the factors. The findings of this study, obtained that fishermen intentions to use floating net cage is influenced by their attitude and subjective norm, while perceived usefulness and perceived ease of use have a role to affect the intentions indirectly.
\end{abstract}

Keywords-Fishermen, Floating Net Cage, Technology Acceptance Model, Theory of Reasoned Action, Survey.

\section{INTRODUCTION}

Offshore aquaculture is one of aquaculture techniques which aims to meet human needs and overcome overfishing issue happening nowadays [1]. Based on that, Pusat Studi Kelautan LPPM ITS is developing floating net cage used for aquaculture, especially for offshore aquaculture. This cage is planned to be placed in Sidoasri Village, Malang, Indonesia. One of the obstacles of this project is fishermen in Sidoasri as potential user. They have no knowledge and experience to use floating net cage and to do aquaculture. Furthermore, their neighborhood, Sendang Biru, has similar product used for aquaculture. Unfortunately, the aquaculture didn't run successfully and failed to gain profit. From the conditions above, can lead fishermen in Sidoasri resist to use this product, so factors influencing their intentions to use need to be identified.

The purpose of this research is to identify factors influencing fishermen intentions to use floating net cage. In this paper we are using Technology Acceptance Model (TAM). TAM is a model to describe user response, so that factors affecting user acceptance can be identified [2]. Then, TAM is integrated with its antecedent theory, which is Theory of Reasoned Action (TRA). TRA is a model that learn the determinants of human's behavior based on social psychology [3], [4]. The integration between TAM and

\footnotetext{
${ }^{1}$ Mokh Suef, Nani Kurniati, and Farras Rahardini Azizah are with Department of Industrial Engineering, Institut Teknologi Sepuluh Nopember, Surabaya, 60111, Indonesia. E-mail: mokhsuef@gmail.com; nanikur@gmail.com; farrasra@gmail.com.
}

TRA aims to accomodate social factor that may affect person's behavior when particular technology is given to them.

This paper proceeds as follows: Section 2 reviews the theoretical background used in this paper. Section 3 introduces research model and hypothesis. Section 4 details the methodology. Section 5 presents data analysis and results. Section 6 discusses the findings obtained and section 7 concludes the overall research in this paper.

\section{THEORETICAL BACKGROUND}

Theory of Reasoned Action. Theory of Reasoned Action (TRA) learns the determinants of human's behavior from social psychology field. Basic theory in TRA is to predict and explain human's behavior in general [3], [4]. TRA consists of several variables, actual behavior, behavioral intention, attitude toward behavior, and subjective norm. Actual behavior of a person is determined by behavioral intention and behavioral intention is determined by attitude toward behavior also subjective norm.

\section{A. Technology Acceptance Model.}

Technology Acceptance Model (TAM) adopted and developed from Theory of Reasoned Action (TRA) for technology usage [5]. This model derived from the need to understand why people resist a technology, so as system evaluation can be conducted, predict user response, and improve user acceptance. TAM consists of several variables, perceived usefulness, perceived ease of use, attitude toward using, behavioral intention to use, and actual system use [2].

\section{B. Research Model and Hypothesis}

Research Model. Model in this paper, proposed based on need to identify factors influencing fishermen intentions in Sidoasri to use this cage. TAM and TRA are integrated to accomodate social factor that may influence person's behavior or decision when particular technology given to them. It is due to their lack of knowledge about floating net cage and failures happened in Sendang Biru on aquaculture. Proposed model in this paper consists of 5 variables, perceived usefulness, perceived ease of use, subjective norm, attitude toward using, and behavioral intention to use as shown in Figure 1. Where perceived usefulness, perceived ease of use, attitude toward using, and behavioral intention to use are variables from TAM, while subjective 
norm, attitude, and behavioral intention are variables from TRA.

\section{Hypothesis Development.}

Each hypothesis exhibits the relationship between variables or constructs indicated by the arrow in the proposed model in Section 3. The hypotheses in this paper are formulated based on basic model used, i.e. TAM and TRA. Where hypothesis $1,2,3,4$, and 5 are formulated based on TAM, while hypothesis 5 and 6 are formulated based on TRA. The hypotheses are given below.

H1 : Perceived ease of use has effect on perceived usefulness.

H2 : Perceived ease of use has effect on attitude toward using.

H3 : Perceived usefulness has effect on attitude toward using.

H4 : Perceived usefulness has effect on behavioral intention to use.

H5 : Attitude toward using has effect on behavioral intention to use.

H6 : Subjective norm has effect on behavioral intention to use.

\section{RESEARCH METHOD}

\section{A. Data Collection}

In this research, data was collected and used to test the formulated hypothesis. Data was obtained through survey questionnaire to fishermen in Sidoasri as potential user of this floating net cage. Survey questionnaire is done for 2 days. To avoid misunderstanding in answering the question, the fishermen are guided to answer each question. From the survey, 24 respondents are obtained of the total 80 fishermen in Sidoasri. They didn't have enough knowledge and experience to use floating net cage and to do aquaculture. After data preprocessing is done, there are only 22 data that can be continued to the next analysis, while the rest is deleted because of missing value.

\section{B. Measurement of Variables/Constructs}

In this paper, variables in the model (referred to as constructs) are measured by using multiple items called indicators. Indicator is a measured variable used to conclude a variable or construct [6]. Based on theory and previous research, indicators for each variable are determined. For perceived usefulness and perceived ease of use, measured by 4 and 3 indicators respectively [7]. For attitude toward using and subjective norm, measured by 3 and 2 indicators respectively [8]. While behavioral intention to use measured by 2 indicators [9]. Indicators for variables or constructs are given in Table 1 with total of 14 indicators. The indicators used to arrange research questionnaire. For all indicators, Likert-type scales were used ranging from strongly disagree (1) to strongly agree (5).

\section{DATA ANALYSIS AND RESUlts}

Data are collected and summarized as depicted in Table 2. Then, the data are analyzed using Partial Least Squares Structural Equation Modeling (PLS-SEM) with Smart-PLS v3.2.7 program. In PLS-SEM, after the model is built and data are collected, model parameters are estimated based on the data obtained. From the estimation results, evaluation is done for measurement model and structural model [10]. Evaluation of measurement model related to indicators used to measure a variable or construct. While evaluation of structural model related to hypothesis testing to identify relationship between variables or constructs.

\section{A. Measurement Model.}

Evaluation of measurement models consists of individual item reliability, internal consistency reliability, convergent validity, and discriminant validity with the following criteria [5], [9].

1. Individual item reliability: loading factor $(\lambda) \geq 0.7$

2. Internal consistency reliability: cronbach's alpha and composite reliability $\geq 0.7$

3. Convergent validity: AVE $\geq 0.5$

4. Discriminant validity: the square root of AVE is greater than the correlation between variables or constructs.

The results for measurement models evaluation for individual item reliability, internal consistency reliability, and convergent validity are shown in Table 3. For individual item reliability, each indicator has loading factor above 0.7. For internal consistency reliability, cronbach's alpha and composite reliability values are above 0.7 for all variables or constructs. Also for convergent validity, AVE value for all variables or constructs are above 0.5 . Then for discriminant validity, the results are shown in Table 4. From the table, obtained that the square root of AVE is greater than the correlation between variables or constructs. From the evaluation of measurement model, can be concluded that indicators in the model have met the criteria and can proceed to evaluation of structural model.

\section{B. Structural Model.}

Evaluation of structural models begins with collinearity test. Model is indicated collinear if VIF value exceed 5. Then hypothesis test is done to identify relationship between variables based on $p$ value. If $p$ value $<\alpha$ then, there is relationship between variables or constructs, otherwise there is no relationship between variables or constructs (in this paper using $5 \%$ of significance level) [10]. From collinearity test, the model is not indicated collinear with VIF value below 5 for all variables or constructs. Then continued with hypothesis testing and obtained the results as shown in Figure 2. Based on the results, perceived ease of use has no influence toward perceived usefulness, in other words, the result didn't support for H1. But perceived ease of use has influence toward attitude toward using (with p value $<0.05$ ) and the result support for H2. Perceived usefulness has influence toward attitude toward using and the result support for $\mathrm{H3}$. But perceived usefulness has no influence toward 
behavioral intention to use and the result didn't support for H4. Attitude toward using has influence toward behavioral intention to use and the result support for H5. While subjective norm has influence toward behavioral intention to use and the result support for H6.

\section{DISCUSSION}

From the analysis, several relationships are not in accordance with the basic theory. In TAM, perceived ease of use has effect on perceived usefulness and perceived usefulness has effect on behavioral intention to use [2]. While the relationship between perceived ease of use toward perceived usefulness and perceived usefulness toward behavioral intention to use are not proven on the analysis. It is in contrast to the previous research, where attitude toward using not included in final TAM because perceived usefulness can directly influence behavioral intention to use without using attitude toward using as mediator [11].

After the model has been adjusted or re-specified, the model consists of 4 relationships. Behavioral intention to use is determined by attitude toward using and subjective norm. Then attitude toward using determined by perceived usefulness and perceived ease of use. From the final model, obtained R2 value $=0.676$ for behavioral intention to use . From the value obtained, it can be concluded that behavioral intention to use mainly determined by its antecedents, i.e. attitude toward using and subjective norm. While R2 value for attitude toward using achieve 0.593 and it can be concluded that attitude toward using mainly determined by its antecedents, i.e. perceived usefulness and perceived ease of use. Even though perceived usefulness and perceived ease of use didn't directly influence behavioral intention to use, they influence behavioral intention to use indirectly through attitude toward using.

\section{CONCLUSION}

From this research, factors influencing fishermen intentions to use this cage by integrating TAM and TRA have been identified. Factors directly influencing fishermen intentions are attitude toward using and subjective norm. Also factors indirectly influencing fishermen intentions are perceived usefulness and perceived ease of use through attitude toward using. It can be used to support this cage before it is implemented in Sidoasri, regarding factors influencing fishermen intentions.

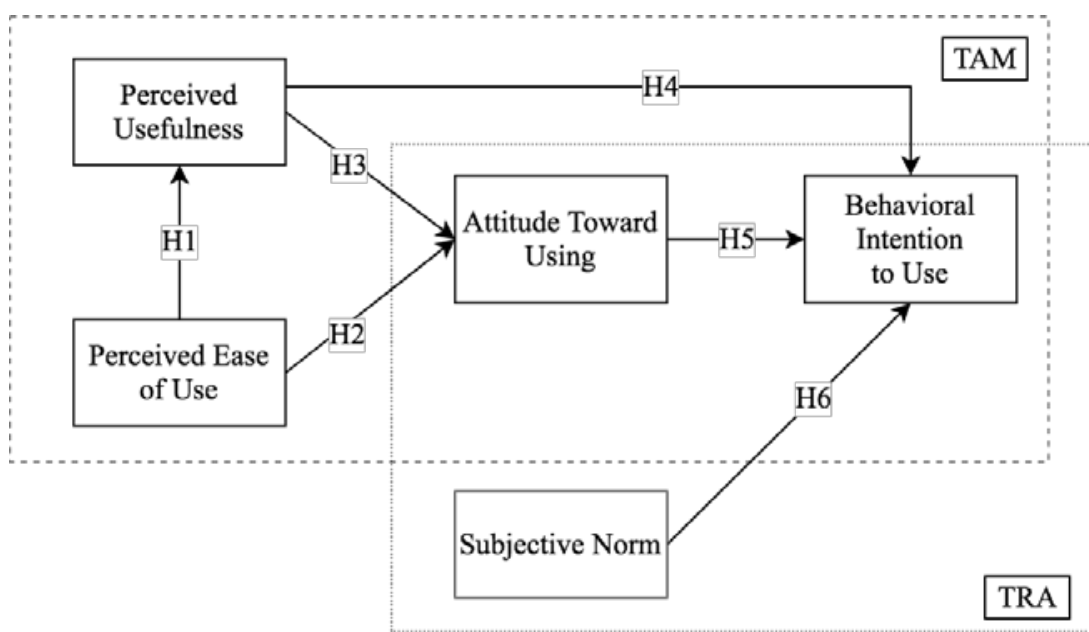

Figure 1. Proposed Research Model.

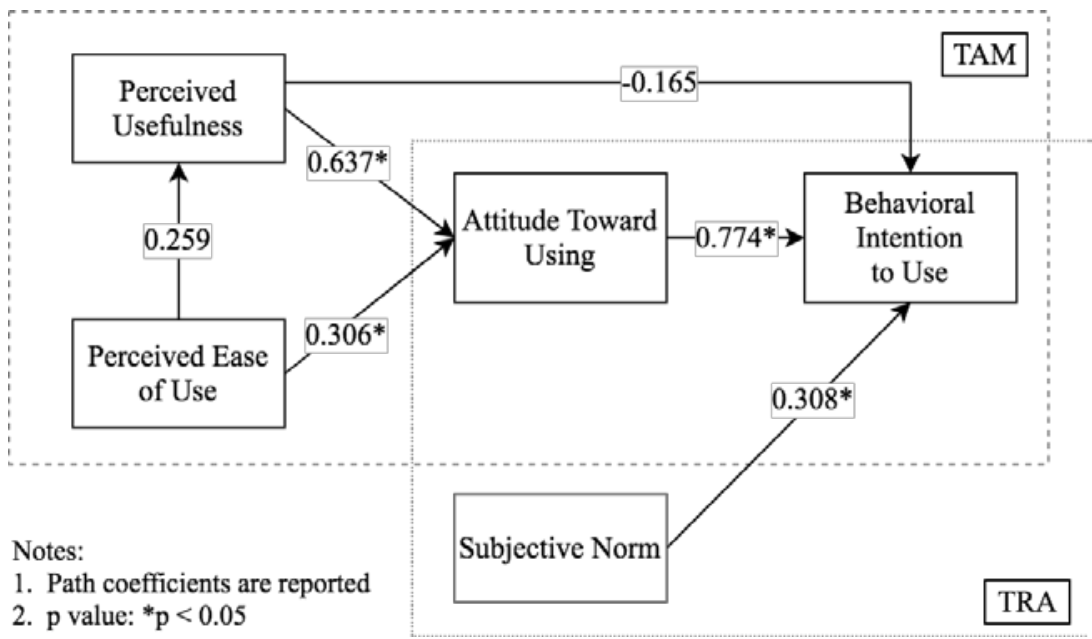

Figure 2. Structural Model Evaluation Result 
TABLE 1.

INDICATOR OF VARIABLES/CONSTRUCTS

\begin{tabular}{|c|c|c|}
\hline $\begin{array}{c}\text { Variables/Constructs } \\
\text { Constructs }\end{array}$ & & Indicators \\
\hline \multirow{4}{*}{ Perceived Usefulness } & PU1 & Using this floating net cage would increase my productivity \\
\hline & PU2 & Using this floating net cage would enhance my effectiveness on the job \\
\hline & PU3 & Using this floating net cage would make it easier to do my job \\
\hline & PU4 & I would find this floating net cage useful in my job \\
\hline \multirow{3}{*}{ Perceived Ease of Use } & PEOU1 & Learning to operate this floating net cage would be easy for me \\
\hline & PEOU2 & It would be easy for me to become skillful at using this floating net cage \\
\hline & PEOU3 & I would find this floating net cage easy to use \\
\hline \multirow{3}{*}{ Attitude Toward Using } & ATU1 & Using this floating net cage is a good idea \\
\hline & ATU2 & Using this floating net cage is a wise idea \\
\hline & ATU3 & I like the idea of using this floating net cage \\
\hline \multirow{2}{*}{ Subjective Norm } & SN1 & People who are important to me would think that I should use this floating net cage \\
\hline & SN2 & People who influence my behavior would think that I should use this floating net cage \\
\hline \multirow{2}{*}{$\begin{array}{c}\text { Behavioral Intention } \\
\text { to Use }\end{array}$} & BI1 & I intend to use this floating net cage \\
\hline & BI2 & Given that I had access to this floating net cage, I predict that I would use it \\
\hline
\end{tabular}

TABLE 2.

MEASURES OF TECHNOLOGY ACCEPTANCE

\begin{tabular}{ccc}
\hline \hline Variabel Laten & Indikator & Rata-rata \\
\hline Perceived Usefulness & PU1 & 4.045 \\
& PU3 & 3.864 \\
Perceived Ease of Use & PU4 & 4.909 \\
& PEOU1 & 2.182 \\
\hline Attitude Toward Using & PEOU2 & 3.182 \\
& PEOU3 & 3.091 \\
\hline Subjective Norm & ATU1 & 4.182 \\
& ATU2 & 4.000 \\
& ATU3 & 4.273 \\
& ATU4 & 3.773 \\
\hline \hline & BI1 & 4.182 \\
& BI2 & 4.364 \\
& BI3 & 3.455 \\
\hline
\end{tabular}

TABLE 3.

LOADING FACTOR, CRONBACH'S ALPHA, COMPOSITE RELIABILITY, AND AVE RESUlTS

\begin{tabular}{cccccc}
\hline \hline Variables/Constructs & Indicators & Loading & Cronbach's alpha & Composite Reliability & AVE \\
\hline ATU & ATU1 & 0.81 & 0.795 & 0.88 & 0.71 \\
\cline { 5 - 6 } & & & &
\end{tabular}




\begin{tabular}{|c|c|c|c|c|c|}
\hline & ATU2 & 0.865 & & & \\
\hline & ATU3 & 0.852 & & & \\
\hline \multirow{2}{*}{ BI } & BI1 & 0.913 & \multirow{2}{*}{0.734} & \multirow{2}{*}{0.881} & \multirow{2}{*}{0.788} \\
\hline & BI2 & 0.862 & & & \\
\hline \multirow{3}{*}{ PEOU } & PEOU1 & 0.797 & \multirow{3}{*}{0.832} & \multirow{3}{*}{0.9} & \multirow{3}{*}{0.752} \\
\hline & PEOU2 & 0.864 & & & \\
\hline & PEOU3 & 0.934 & & & \\
\hline \multirow{4}{*}{ PU } & PU1 & 0.838 & \multirow{4}{*}{0.923} & \multirow{4}{*}{0.941} & \multirow{4}{*}{0.8} \\
\hline & PU2 & 0.884 & & & \\
\hline & PU3 & 0.903 & & & \\
\hline & PU4 & 0.95 & & & \\
\hline \multirow{2}{*}{ SN } & SN1 & 0.98 & \multirow{2}{*}{0.966} & \multirow{2}{*}{0.983} & \multirow{2}{*}{0.966} \\
\hline & SN2 & 0.986 & & & \\
\hline
\end{tabular}

TABLE 4.

DISCRIMINANT VALIDITY RESULTS

\begin{tabular}{cccccc}
\hline \hline & ATU & BI & PEOU & PU & SN \\
\cline { 2 - 5 } ATU & $0.843^{* *}$ & & & & \\
BI & $0.763^{*}$ & $0.888^{* *}$ & & & \\
PEOU & $0.471^{*}$ & $0.519^{*}$ & $0.867^{* *}$ & & \\
PU & $0.716^{*}$ & $0.427^{*}$ & $0.259^{*}$ & $0.895^{* *}$ & \\
SN & $0.348^{*}$ & $0.558^{*}$ & $0.265^{*}$ & $0.123^{*}$ & $0.983^{* *}$ \\
\hline \hline Notes: & & & & \\
** Square root of AVE & & & & \\
* Correlation between variables/constructs & & &
\end{tabular}

\section{REFERENCES}

[1] I. Effendi and Mulyadi, "Budidaya Perikanan,” 2012.

[2] F. D. Davis, R. P. Bagozzi, and P. R. Warshaw, "User acceptance of computer technology: A comparison of two theoritical models," Manage. Sci., vol. 35, no. 8, pp. 982-1003, 1989.

[3] I. Ajzen and M. Fishbein, Understanding attitudes and predicting social behavior. Englewood Cliffs, New Jersey: Prentice Hall, 1980.

[4] M. Fishbein and I. Ajzen, Belief, attitude, intention and behavior: An introduction to theory and research. Reading, Massachusetts: Addison-Wesley, 1975.

[5] F. D. Davis, "A technologyacceptancemodel for empirically testing new end-user information system: Theory and results," Massachusetts Institute of Technology, 1985.

[6] S. Yamin and H. Kurniawan, Generasi baru mengolah data penelitian dengan Partial Least Square Path Modeling. Jakarta: Salemba Infotek, 2011.
[7] F. D. Davis, "Perceived usefulness, perceived ease of use, and user acceptance of information technology,” MIS Q., vol. 13, no. 3, pp. 319-339, 1989.

[8] S. Taylor and P. A. Todd, "Understanding information technology usage: A test of competing models," Inf. Syst. Res., vol. 6, no. 2, pp. 144-176, 1995.

[9] F. D. Davis and V. Venkatesh, "A critical assessment of potential measurement biases in the technology acceptance model: Three experiments," Int. J. Human-Computer Stud., vol. 45, pp. 19-45, 1996.

[10] J. F. Hair, G. T. M. Hult, C. M. Ringle, and M. Sarstedt, A primer on partial least squares structural equation modeling (PLS-SEM). California: SAGE Publication, Inc., 2013.

[11] V. Venkatesh and F. D. David, "A model of the antecedents of perceived ease of use: Development and test,” Decis. Sci., vol. 27, no. 3, pp. 451-481, 1996. 